\title{
\#mysanfrancisco: Social Media and the Conceptual Linguistic Landscape
}

\author{
Kate Lyons \\ University of Illinois at Urbana-Champaign
}

\begin{abstract}
Recent attempts to advance the field of Linguistic Landscapes (LL) have emphasized the importance of contending with the 'actors' of the LL and their role in interpreting or interacting with language in place (Waksman and Shohamy 2016; Barni and Bagna 2015; Malinowski 2009). This paper addresses this interest in what I refer to as the LL's interpretant (à la Peirce 1955) or conceptual aspect by analyzing representations of physical space posted on Instagram, a popular photo sharing platform. Using a corpus of Instagram posts geotagged within the Mission District in San Francisco, California, I employ methods such as topic modeling and sentiment analysis to investigate the ways individuals are seen to engage with the semiotic landscape of the neighborhood and explore how the Mission itself is discursively constructed through these subjective recontextualizations. In doing so I aim to highlight aspects of the relationship between social media and physical place and the ways language is seen to mediate this dynamic. I argue geographically tagged social media is not representative of an LL but productive, viewing the selective and subjective displays found online to be as much a part of the LL context as a potential key to understanding it.
\end{abstract}

Keywords: Linguistic Landscapes, Social Media, Text Mining, Topic 
Modeling, Ethnographic Methods, Gentrification

\section{Introduction}

The field of Linguistic Landscapes (LL) encompasses study of any type of displayed language in the public space. While a great amount of research in LL has been conducted using a primarily etic approach, the incorporation of local perspectives on sign significance has more recently been emphasized as a way to balance those of the researcher and gain a more holistic understanding of the relationships at work between place, sign and people (Dunlevy 2016; Peck and Banda 2014; Blommaert 2013; Lou 2010; Garvin 2010; Malinowski 2009). As discussed in Monica Barni and Carla Bagna's recent overview, LL has grown significantly from its beginnings in quantitative approaches concerned with the counting of languages and signs in the attempt to gauge linguistic vitality to a discipline in its own right, concerned not only with the documentation of languages' public presence, but the complex relationship between language, place and people (2015). This expansion in scope has witnessed a parallel development of methods, both quantitative and qualitative, used to catalog and discuss the LL both in and of itself as well as its wider social significance (Blackwood 2015; Blommaert 2013; Stroud and Mpendukana 2009). As the field continues to revisit, redefine and refine its theory and methods, one central question as come increasingly into focus: how and to what extent do people engage with the LL?

It is this concern, the "authors and actors" of the LL (Barni and Bagna 2015: 7) that this paper attempts to address in two ways: 1) by demonstrating the value of social media platforms (SMPs) as a source of LL Interpre- 
tants and 2) considering the social media platform not as representative of the physical LL, but productive - understanding the selective and subjective recontextualizations to be as much a part of the LL context as a key to understanding it. It is in this sense that the idea of SMPs as 'virtual' is found to be quite misleading, as the recontexualizations of place that are geotagged posts are shared within a social network in a very analog sense: via interpersonal relationships and semiotic chains (Agha 2007) through which discourses of what a place is and what a place means are generated and circulated. The SMP is thus positioned as a means to observe and track the complex semiotic processes through which place is produced as well as an instrument with which relationships between people and place are enacted. Such a position both enriches our growing understanding of how SMPs work and what functions they serve as well as the semiotic mechanisms used to achieve them.

To track such mechanisms, I employ qualitative and quantitative methods from LL, computational linguistics and corpus linguistics. In so doing I hope to highlight the potential benefits of using techniques such as data mining, sentiment analysis and topic modeling for LL studies and beyond as well as contend with the limitations of such approaches for sociolinguistic research. I conclude, however, that when the assumptions of quantitative inference are balanced with those of qualitative interpretation significant insights can still be achieved. 


\section{Linguistic Landscapes and Social Media Platforms}

Viewing posts of LLs on SMPs as productive and processual rather than representative and fixed is a fitting parallel to developments within the field of LL itself. Public signs no longer serve as counts of ethnolinguistic vitality, but as agents of spatialization: constituting "social, linguistic and political structures" that inform as much as reflect a locale's ideological makeup (Blommaert 2013: 3; Ben-Rafael et al. 2006; Shields 1987; Lefevbre 1991; Foucault 1984). Contemporary LL research is situated in the middle of this dynamic, concerned with how we may understand the presence of some languages or scripts over others (Blackwood 2015; ${ }^{1}$ Amos 2016), the representation or commodification of language (Jaworski 2015; Coupland 2012) and the ways in which language display may inform our understanding of the effects of increasingly pervasive processes such as globalization (Vandenbroucke 2016) and gentrification (Lyons and Rodríguez-Ordóñez 2015; Papen 2012).

Of equal importance, yet perhaps underrepresented as yet in current research, are the so-called 'actors' of the LL: sign producers, observers and passers-by. Attention to the production component has been tackled in part with discussion of "top-down" and "bottom-up flows" which are said to "order" the LL: top-down consisting of institutions and bottom-up more autonomous individual or corporate actors (Ben-Rafael et al. 2006; cf. Gorter 2006; Cenoz and Gorter 2006; Backhaus 2006 and other chapters in Linguistic

\footnotetext{
${ }^{1}$ As Blackwood (2015) notes, contemporary research on minority language presence does not argue counts to be representative of vitality; rather that an evaluation of frequency provides insights on the attitudes or beliefs of the community towards language(s) (39).
} 
Landscape: A New Approach to Multilingualism). This approach has been critiqued by Kallen (2010) for assuming "different types of signage are in opposition within the same system", an assumption of inherent competition that is problematic, as it presupposes the LL to be homogenous, disregarding the fact that signs (as well as their creators or posters) have different and independent origins, constraints, motives and levels of conscious planning (42). Instead, Kallen advocates for viewing the LL in terms of frameworks "defined by the functions of discourse entered into by interlocutors and by the language choices and forms of expression available to these interloctors", comparable to Erving Goffman's conception of discourse frames (Ibid.: 43; Goffman 1974).

Application of frame analysis emphasizes attention to the interactional context of the sign (Kallen 2010; Coupland and Garrett 2010; Jaworski and Yeung 2010; Coupland 2012; Lyons and Rodríguez-Ordóñez 2015), drawing from Goffman's (1974) formulation of a frame as a representation of how individuals understand and contextualize experiences. Within the LL, frames describe processes of context building through which a sign may signal its audience or purpose through a number of semiotic choices: Kallen (2010) describes the use of official insignia or prescribed shapes (such as the octagon of the categorical Stop sign) in constructing a civic frame of "activities of the state" (46-47); Coupland (2012) highlights how the Welsh language itself can be cued as a nationalist resource or an exotified tourist commodity.

Discussion of frames acknowledges signs' potential to project a particular context for its viewers, and does somewhat bring these viewers into account: Coupland brings up the need for "mutual awareness" of displayer 
and viewer for a sign to be effective (2012: 5). Frame analysis thus does much to recognize the inherently subjective nature of sign intent and interpretation, nuancing the ways in which one can argue a sign to index $\mathrm{X}$ or $\mathrm{Y}$ within a community. The index, however, is only one part of how signs in the LL (and signs in a more general sense) can be understood to work. If we are to consider signs in terms of Charles Sanders Peirce's formulation, as use of the idea of the index would suggest, signs are thought of in terms of the relationships they establish. Peirce proposes the sign as "something which stands to somebody for something in some respect or capacity" (Peirce 1955: 99), advocating the sign (or the process by which a sign stands for something to someone) as tripartite. The components of this sign-action are the Object (the 'something' the sign represents); the Representamen (referred to also as the 'sign' or 'sign-vehicle', the 'something' represented in physical dimensions) and the Interpretant (the 'something' as represented to 'somebody' or the 'something' that is created in the mind of the 'somebody').

To put this in perspective of the LL, a physical sign nailed to the side of a building or painted on a window can be thought of as the Representamen, the desire or intentions of the owner of the establishment the Object (the owner wishing to communicate the establishment is there, the times at which it is open, whether or not there is a sale going on, etc.) and the Interpretant that which the physical sign brings about in the mind of anyone who views the Representamen ("Oh! There's a sale on!" "Who buys VCRs anymore?" "How pretty", etc.). The bulk of LL research has focused on the Representamen and the processes (predominately indexical) by which these signs denote their Object. The 'somethings' LL signs give rise to in a more general 
sense, its Interpretant aspect, apart from those interpretations we as analysts make, has gone relatively over-looked. Previous work that has attempted to engage with the ways in which individuals interact with the LL has done so through the use of interviews (Papen 2012) or through a presentation of an area?s ethnography or in-depth socio-cultural history and context (Stroud and Mpendukana 2009; Blommaert 2013). To these approaches I introduce use of social media platform data as a way of gauging the varied subjective meanings the LL generates for people.

Social media has itself been discussed as its own landscape or Semiotic/Linguistic Landscape (Jones 2010; Ivkovic and Lotherington 2009) and in many ways one might think of it as a place one can 'go' or 'be'. Sociolinguistic understandings of social media have mostly focused, however, on conceptualizing it within the "social web" or "Web 2.0", terms used to describe "platforms characterized by social interaction and user-generated content" (Herring 2012: 1; Sykes et al. 2008; Zappavigna 2011; boyd and Ellison 2007). In this sense social media has been primarily discussed either in terms of the grammar of SMP language use, such as lexical variation in Twitter posts (Gouws et al. 2011); variation of SMP-specific language (so-called "e-grammar" à la Herring 2012) or the communicative functions certain behaviors or activities perform: code-switching or "translingual practices" on Facebook as a means of negotiating linguistic authenticity (Dovchin et al. 2015) for example, or the potential for hashtags on Twitter to develop solidarity or affiliation with a large audience (Zappavigna 2011; 2014).

Social media is thus recognized as a medium and a context within itself: both a means or place of communicating as well as a particularized interactive 
construct in which specific communicative norms, registers and ideologies are at work. A post on Twitter is fundamentally different than a post on Facebook, in terms of audience and appearance, but most importantly in terms of the functions of that post that are rooted within the culture of the platform itself.

This mimicking of the ideological contextual constraints of physical space is just one parallel between the analog and the digital, of course, but its consideration is significant when discussing what the higher ordered indexical meanings of SMP posts or activities. For example, take the use of hashtags on Twitter versus hashtags on Instagram: on both platforms hashtags serve as indexes in three senses, as indexes in a more colloquial sense (clicking on a hashtag will lead you to a list of posts tagged with the same word); in a metapragmatic sense as well as functioning as higher-ordered indexes (Silverstein 2003). Hashtags on Twitter and Instagram (and Facebook, for that matter, though less common) have an explicit metapragmatic function in describing or explaining (as well as bringing about) the context in which they are operating, be it to hashtag as a ways of signaling a topic under discussion or as a means of signaling irony (Zoladz 2014) and a corresponding implicit function in which its use assigns properties to the semiotic 'code' of the hashtag itself, working to predict and regiment its meaning (Squires 2010; Silverstein 2003: 196; Agha 2007).

This metapragmatic function, like that of any indexical, is suspended in a feedback loop with ideological structures of value in which the metapragmatic function is (re-)assigned and (re-)negotiated: in the context of Social Media, what a hashtag "does" and "means" on Twitter theoretically changes each 
time one is used, as it does on Instagram, resulting in varying norms and values for hashtags dependent on the platforms themselves as well as for the different individuals or groups of individuals operating within them. The byproduct of this is seen in the third sense in which we may consider hashtags on SMPs: as operating within higher-orders of indexical meaning. As indexicals, hashtags predict and regiment their use and that use in turn is imbued with cultural value: \#yolo, for example, (denoting the acronym for "you only live once") is observed not only as a way of describing or explaining one's post ("going skydiving today!!! \#yolo") or signaling an ironic shift ("decided to go full fat with the morning latte \#yolo") but as belonging to a particular register of a social type (i.e. "figure of personhood" à la Agha 2007; 2011; Squires 2010). "\#yolo" belongs to the imagined Millennial arsenal, flanked by "\#selfie", "\#tbt", "\#win" and others thought to make up the apathetic narcissist social media vernacular (Author, forthcoming).

Platforms can be argued to have their own corresponding registers as well. For example, Instagram's platform-specific hashtags "\#instagood" or "\#instadaily" are hashtags that index in the first sense photos to be entered or considered to be featured in other higher-profile Instagram accounts as "photos of the day" or Instagram photos of note; in the second sense a popular tag explaining the post as a categorical or conventional Instagram post; the third an adept Instagram "regular" figure of personhood or "someone trying to get more followers" and/or the "wannabe Instagram star" figure, ad infinitum. Software specific features can also be seen to shape platform registers: Instagram's lack of character limit can be argued to have lead, or at least facilitated, the practice of hashtag rich post codas, an example of 
which can be found in Figure 5 - a practice that is not only not possible on Twitter, but somewhat contextually out of place.

The indexical mechanics of hashtags, social media registers and figures of personhood are as varied and numerous as their more conventionally discussed analog counterparts: in and of themselves not particularly surprising, perhaps, but whose acknowledgment is key in our discussion of the digital life of physical space. A picture of the LL is a recontextualization of a particular kind like any photograph, and the act of posting such a recontextualization on an SMP like Instagram must be considered within the contextualization practices of the platform itself - much like a photo of an LL hanging in an art gallery is considered differently than that published in an academic journal.

It is in this sense we may think of recontextualizations of place on the SMP as both occupying and ordering both LL and SMP simultaneously: a post of a geotagged picture at once 1) captures a moment in the LL; 2) "indexically invokes" platform-specific meanings and values (Silverstein 2003: 202); 3) implicitly assigns properties to the activity of posting on the platform and 4) implicitly assigns properties to the place itself. I now present examples of these processes taken from my research site, the Mission District in San Francisco, California and introduce quantitative methodological options with which to investigate them on a large scale.

\section{Methods and Research Site}

The data for this project are sourced from Instagram, a popular photosharing platform. Founded in 2010, Instagram claims a "community of more than 500 million who capture and share the world's moments on the service" 
("About Us" 2016). A 2014 study conducted by the Pew Research Center suggested that Instagram was the fastest growing social media platform (compared to Facebook, LinkedIn, Pinterest and Twitter) with a 9\% increase in adult users from 2013 to 2014 (Duggan et al. 2015). Of all adults (users 18 and over) online, the largest percent using Instagram were individuals between 18 and 29. While it was not possible to obtain demographic information for the Instagram users whose data is discussed in this paper, it is likely that most posters were under 35 years of age.

10,208 Instagram posts were collected via Twitter's Search Application Programming Interface using the twitteR package (Gentry 2015) for R during a four-month period between August and November 2016. The term "Application Programming Interface" or API refers in this instance to a tool used by a website to provide and mediate access to website data. The Twitter Search API, part of the REST API, provides "methods for developers to interact with Twitter search and trends data", in particular "queries against the indices of recent or popular Tweets", serving a similar function as the "Search" feature on the Twitter mobile application or Twitter.com ("The Search API"). Tweets matching the criteria of a developer request going back seven days from the time of the request are provided along with metadata such as exact time of posting and the source of the post. An important aspect to note of data obtained from the Search API is that it is "focused on relevance and not completeness" - meaning not all available Tweets are provided in the response to a call ("The Search API"). As such, any data collected cannot be described as comprehensively representative ? a consideration, however, that must be taken with mined social media in general as a 
whole (Danneman and Heimann 2014). An additional limitation to the representativeness of the data presented is that Instagram posts collected were only those cross-posted on Twitter, due to unfortunate limitations of Instagram's API. Posts collected here were thus obtained with a call to Twitter's API for tweets geotagged within a $1 \mathrm{~km}$ radius of the center of the Mission (exact coordinates $37.76^{\circ} \mathrm{N} 122.42^{\circ} \mathrm{W}$ ) and then filtered for those tweets with "instagram.com" as a source.

As the data presented here are limited both by where they were found and who created them (i.e. content generated by a sub-population of individuals who use Instagram further divided by those who have Twitter accounts and cross-post to Twitter, further limited by those posts provided by Twitter's API) it is important to reiterate that insights gleaned from these data are not taken as wholly representative of what all individuals think of the neighborhood or the encompassing context of the neighborhood itself. Rather, what is observed to be said on Instagram is seen as a selective parallel to the Mission's physical confines, providing access to the processes by which place gives rise to Interpretants and the ways in which these subjective recontextualizations are seen to shape place in turn.

Posts analyzed are all geotagged within the Mission District in San Francisco, California. Located in the central-Eastern part of the city, the Mission has been inhabited for approximately 5,000 years, settled initially by the Yelamu, a coastal Native American tribe of the Ohlone language family. The first major urban developments, in which the area turned into a major commercial and residential zone, occurred after the 1906 earthquake when damage to residences to the north, particularly in the South of Market area, 
caused many abandon their original plots and build anew in the Mission.

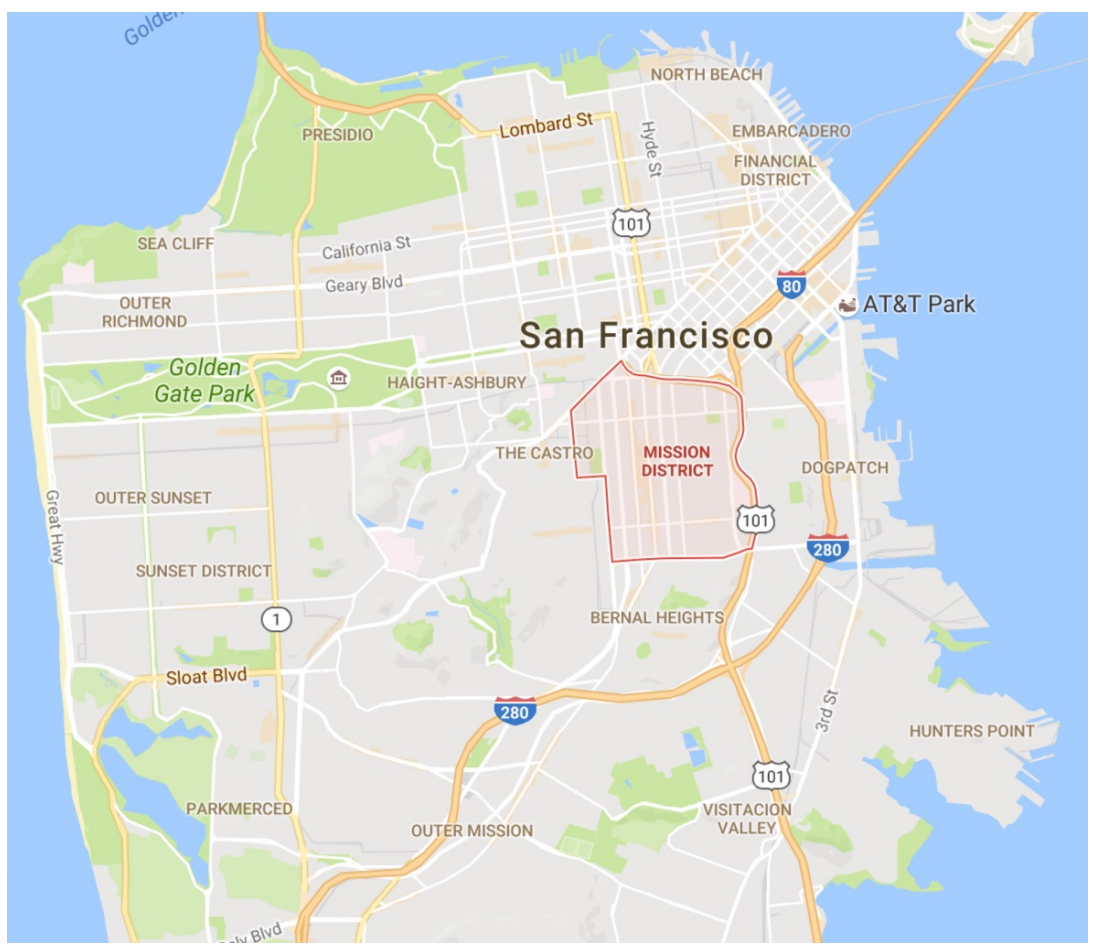

Figure 1: The Mission District, San Francisco ${ }^{2}$

267 During and after the 1906 reconstruction boom the area was predominately occupied by Irish, German and Polish immigrants. These demographics began to change, however, after the post-WWII suburbanization of San Francisco white middle-class families - a phenomenon better known as "white-flight" (Macris et al. 2007). During this period from the 1940s to 1960s, the Mission saw a large increase of immigrant residents predominately from Mexico, followed by an influx of immigrants from Central America beginning in the 1960s. From 1950 to 1970 the Hispanic population in the area

\footnotetext{
${ }^{2}$ Map obtained with the ggmap package in R (Kahle and Wickham 2013).
} 
grew from $11 \%$ to $45 \%$, the northern part of the neighborhood serving as a "gateway" of affordable apartments for more recently arrived Latino and Asian immigrants and the residential south populated by more established (predominately Latino) immigrant families. 24th street in particular grew to be a "banner corridor for Latino culture" with shops, restaurants and other businesses catering to primarily Spanish-speaking residents (Ibid.: 87).

Beginning in the early 1970s, the Mission District began to undergo gentrification. First used to describe the movement of wealthy suburbanities to inner-city London by sociologist Ruth Glass in 1964, the term gentrification now refers to the process by which capital is transferred to urban areas with a recent history of limited investment and an average to low income population. This capital is both economic and cultural, taking shape in extensive public and private property investment and dramatic shifts in bourgeois attitudes towards the desirability of living in or visiting such areas (Glass 1964; Smith 1979). Gentrification entails physical and ideological displacement of pre-gentrification residents, as public or affordable housing is razed or rentcontrol protected residents are evicted to make way for higher paying tenants. Cultural dynamics of neighborhoods change as businesses and services catering to the needs and budgets of the established are replaced with those that serve the interests of the privileged newcomer. In the context of the United States, in which race and ethnicity have a systemic correlation with socioeconomic status, the disruption of gentrification predominately affects historically non-white neighborhoods and communities. It is in this sense gentrification can be understood as a violent re-defining of the public space, a "new urban colonialism" by which "a white Anglo appropriation of urban 
space and urban history" is asserted (Atkinson and Bridge 2005: 2).

The transfer of capital to the Mission began in the early 1970s with the construction of two Bay Area Rapid Transit (BART) subway stations on the intersection of 16th Street and Mission Street and 24th Street and Mission Street. Despite significant protest from Mission residents on the impact of destructive BART construction on local businesses and the threat of "increased land values" from increased connectivity to San Francisco's downtown making "large apartment houses more profitable and desirable for landlords" ("BART Changes the Mission" 1970) the stations were completed in 1972.

Land costs indeed begin to increase in the neighborhood, but stayed under the city-wide median. This began to change, however, in the mid-1990s with the 'dot com boom' centered in the Santa Clara Valley area south of San Francisco nicknamed 'Silicon Valley'. Due to its proximity to Highway 101 and (relatively) lower rents, the Mission became a popular neighborhood for individuals working in Silicon Valley during the first tech bubble in the late 1990s and early 2000s. At this time median property values in the Mission exceeded the city-wide median and the Hispanic population first began to show a decline (?A Changing Mission? 2014). This trend slowed after dotcom crash in 2000, but began picking up (seemingly) exponentially until the present day, with the white population increasing by more than $20 \%$ since 2010 and no-fault evictions doubling to $62 \%$ since 2009 .

Discussions and debates surrounding the gentrification of the Mission are extremely prevalent aspects of its sociopolitical context and climate. Demonstrations protesting increasing no-fault evictions and zonings of new devel- 
opments are a frequent occurrence up north at City Hall as well as within the neighborhood ("Mission District anti-eviction protestors take over SF City Hall" 2015). Significant protests within the Mission include those targeting so-called "Google Buses" - sleek white chartered buses hired by tech companies to shuttle their Mission-residing employees south to Palo Alto or Mountain View. Protests blocking "techie" chartered buses continued from late 2013 throughout 2014, making international news headlines as well as pressuring the San Francisco Municipal Transportation Agency to begin charging charter operators for use of city bus stops ("Google Bus Backlash: S.F. to impose fees on tech shuttles" 2014). Protest and critique of recent changes to the Mission are also etched and echoed in the Mission landscape: sites of evictions demarcated in spray paint; murals calling to "Evict Google"; posters depicting chartered buses stopping at "\#affluenza"; passersby audibly scoffing at the newest "yuppie" or "techie" coffee shop.

While considerable criticism has been directed towards the "techies" for the Mission's racial and socioeconomic change, no problem is ever so simple: as Smith (1979) and others point out, gentrification can better be understood as the movement of capital into a city, not only people. Regulations are complicit as much as new renters in the "Changing Mission", a process underscored by privilege and its ever-present racial correlates. There are certainly other things going on in the Mission apart from gentrification, but it must be emphasized that a steady underline of the Mission context is displacement - either undergoing or undergone. The silencing of such a process is as significant as the trumpeting of one - a point of special significance as we turn to the data. 

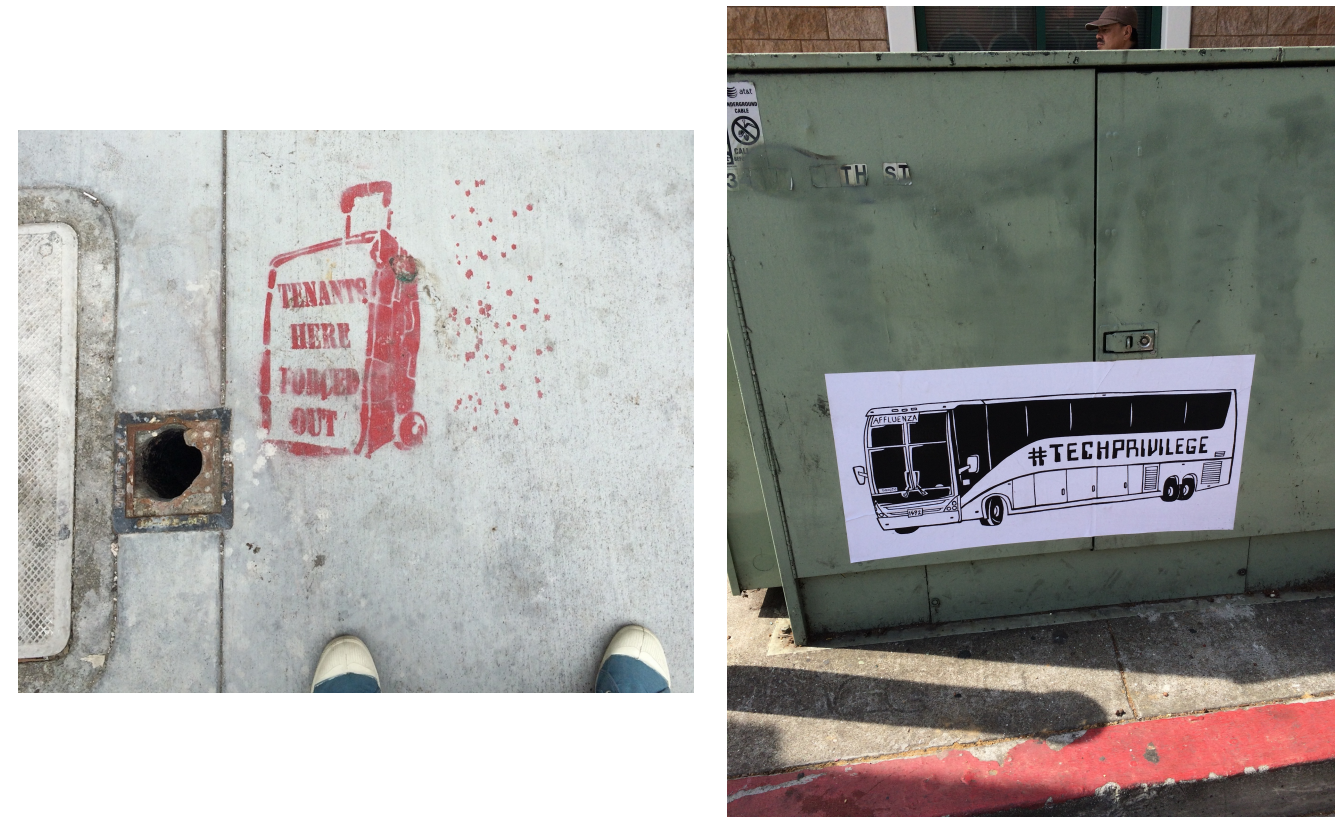

Figure 2: Critiques of Gentrification in the Mission LL

\section{Data and Analysis}

The goal of this paper is to explore the ways in which the LL is both enacted and engendered on social media. These processes can be observed on a smaller scale in the form of individual posts and on a larger, more encompassing level through a corpus obtained through text mining. I will first provide some examples of posts in which individuals are seen to engage and animate the LL, and then present the corpus data and related analyses.

Interactions with the LL on Instagram vary in form and degree of (explicitly apparent) engagement. This is illustrated in Figure 3 and Figure 4: an example of the Mission's LL posted 'without comment', followed by another piece of Mission LL in Figure 4 with an accompanying hashtag commentary.

While no explicit hint to its interpretation is given by the poster of this 


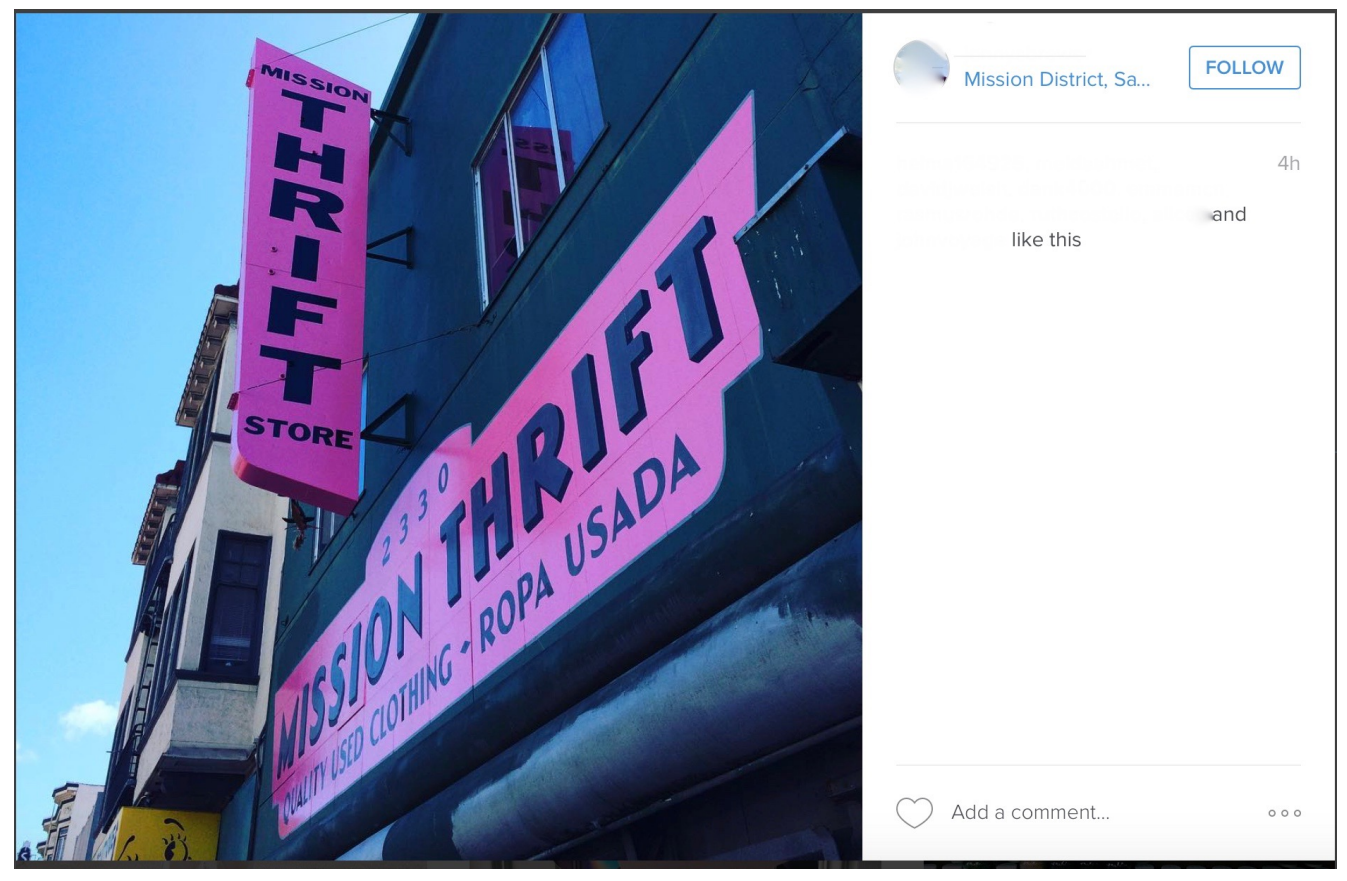

Figure 3: 'No Comment' Mission Thrift

image of the Mission Thrift shop front on 2330 Mission Street, its lack of commentary must be seen as equally significant as the text provided in Figure 4 and 5. No comment is one of the ways in which individuals may 'interact' and produce the LL on social media. While sparse, this production of 2330 Mission Street is nevertheless subjective: framed by a subjective viewer for subjective viewings. This subjectivity is made more apparent in Figure 4, a post of a spray-painted message presumably outside near a private driveway.

The image, like that provided in Figure 3, brings a selective piece of the LL within the digital sphere and further recontextualizes it with the hashtags "\#onlyinsf", "\#mission", "\#weird", "\#weirdsf" and "\#sanfrancisco". Such hashtags as "\#sanfrancisco" and "\#onlyinsf" animate this chunk of the Mission by connecting it to posts with the same tag: the physical LL becomes 


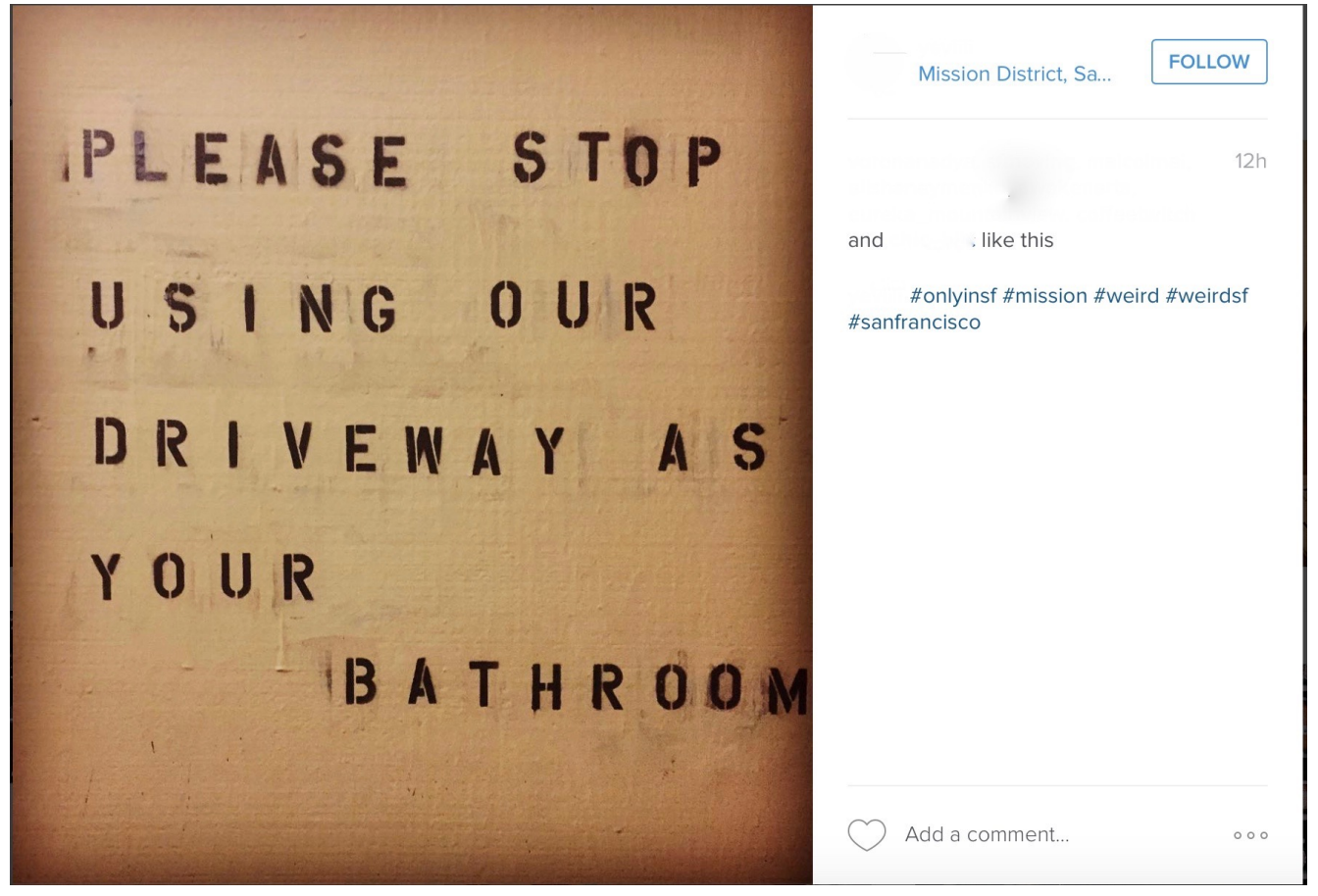

Figure 4: '\#onlyinSF'

the digital LL, a thumbnail in the pixelated gallery generated with a click on one of these tags. The image of the LL is part of what "\#onlyinsf" and "\#weirdsf" can mean and, simultaneously these tags are part of what the LL can mean to an observer. The snapshot of the LL on Instagram and the accompanying comments are therefore not to be understood as representative either of the LL or of its interpretation, but a distinct parallel - a projection or shadow of the physical and conceptual.

While the conceptual LL of Instagram must be considered as parallel and distinct from a theoretical view point, it does not necessarily follow that individuals do not move freely from the physical to the digital or that a impermeable barrier exists between the two. Such fluidity is illustrated 


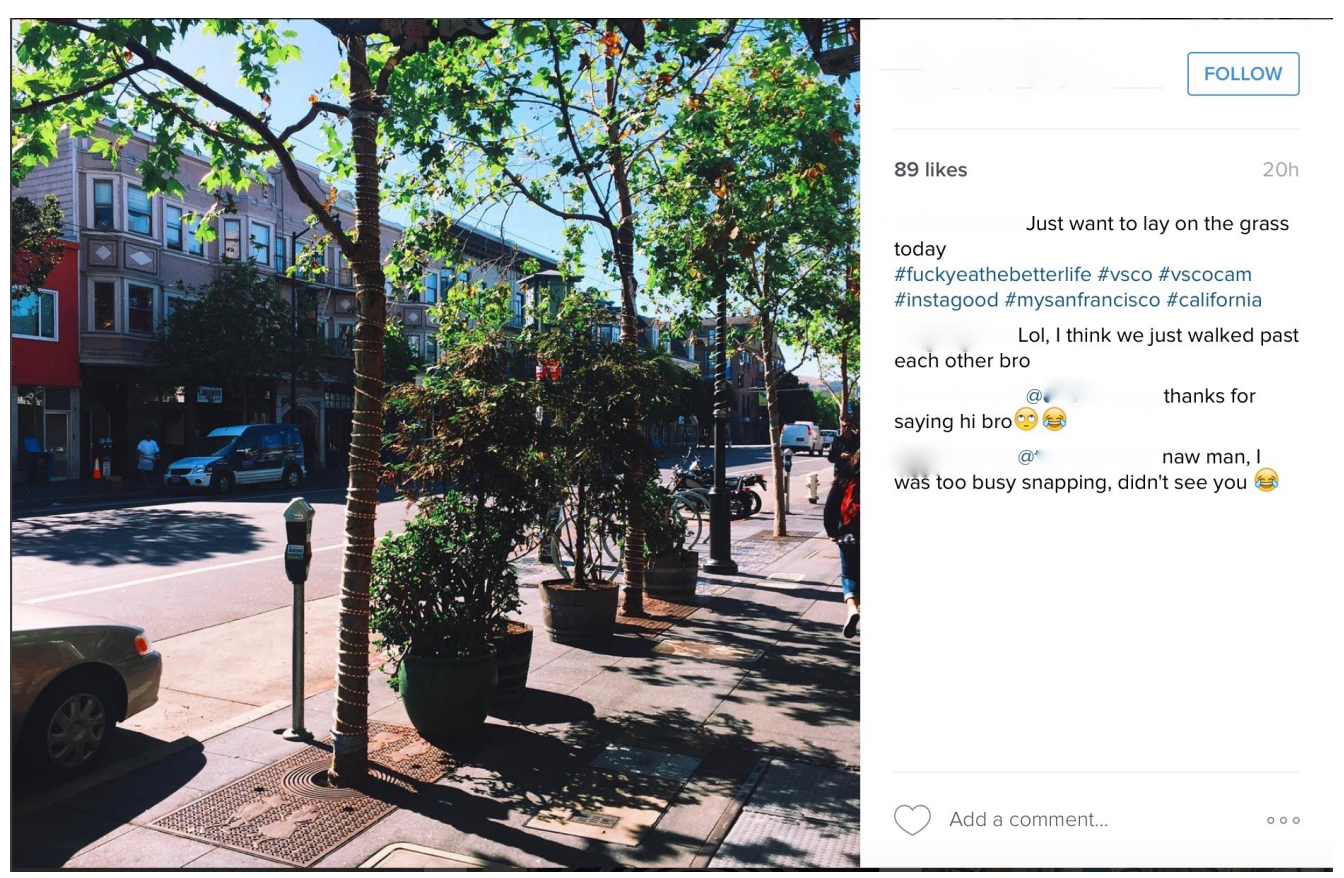

Figure 5: '\#mysanfrancisco'

in the Instagram post shown in Figure 5, in which the boundary between material and virtual space is seen to be very permeable indeed.

Like the example provided in Figure 4, this post contains a piece, albeit less focused, of the Mission District LL with a short prose and hashtag commentary. ${ }^{3}$ In this example, however, another Instagram user is seen to comment: "Lol, I think we just walked past each other bro", to which the poster responds sarcastically "thanks for saying hi bro" with the "face with

\footnotetext{
${ }^{3}$ The hashtags \#vsco and \#vscocam refer to a photography application developed by the Visual Supply Company for smart phones. The VSCO app allows users to take, edit and share photos in a "minimal interface and a wealth of inspired photo-altering tools" ("App Store Editor's Notes"). The hashtag \#vsco and \#vscocam can also be described as part of the social media register of the 'hipster' figure of personhood.
} 
rolling eyes' emoji and 'face with tears of joy' emoji (conventionally understood as strong laughter). The commenter responds: "naw man, I was too busy snapping, didn't see you (face with tears of joy)". In this example we see a curious event: two individuals occupying the same physical space in great proximity yet interacting in the generated conception of the place that exists online as both were 'too busy' engaging with this parallel landscape to notice each other. ${ }^{4}$ It is in moments like this that the tangibility of such aspects are highlighted - 'conceptual' and 'parallel' or even 'digital' do not make these landscapes any less real - here we have an example in which the digital appears to be more tangible than the organic, at least for these two individuals. The tag "\#mysanfrancisco" encapsulates this relationship quite elegantly. 'San Francisco' as a place is here simultaneously material and virtual, objective and subjective: a distinct entity that can nevertheless be claimed and personalized.

While analysis of discrete posts provides important insights on how individuals can be observed to engage with or animate the LL, it is also useful to utilize a larger corpus obtained through text mining to investigate these processes on a more encompassing scale. Such an approach views photos on Instagram as themselves part of an area's LL: as seen in the previous individual examples, geotagged images on social media are not necessarily representative but productive, bringing about a parallel place through their subjective positioning. As such, I argue any geotagged image can be claimed as part of the conceptual LL of social media, even if it does not depict

\footnotetext{
${ }^{4} \mathrm{~A}$ circumstance increasingly more common - at times dangerously so - with augmented reality games or applications such as Pokemon Go.
} 
something perhaps more traditionally classified by researchers as part of the physical LL. Even so, this perspective fits nicely with theoretical conceptions of what an LL is: "any (public) space with visible inscription made through deliberate human intervention" (Jaworski and Thurlow 2010): geotagged images on Instagram do occupy a 'space' of sorts on an Instagram feed and can be assumed to be generated with some degree of deliberation.

To identify the broader patterns present in the conceptual geotagged Mission, I apply sentiment analysis and topic modeling. Before applying these techniques, however, the corpus of 10,208 Instagram posts needed to be 'cleaned' by getting rid of URLs (as these are all re-posts on Twitter each post has a URL to the original Instagram post); corpus-specific insignificant encodings (i.e. "\&amp;" for the symbol "\&"; the phrase "Just posted") and repetitive 'spam' content automatically generated by bots. This phase of processing created some 'empty' documents which were then eliminated, resulting in a corpus of 8,971 posts. I then used the tm package in $\mathrm{R}$ (Feinerer and Hornik 2015) to eliminate white space, punctuation and numbers; turn all terms to lowercase (to eliminate "Park" and "park" being counted as two different terms) and to transform the corpus text into a plain text format for easier processing. Finally, stop words or function words were eliminated from the corpus using a combination of the tm package's built in stop word list and the stop word list provided by the tidytext package in R (Silge and Robinson 2016).

Sentiment analysis, also known as opinion mining, describes the study of "people's opinions, sentiments, appraisals, attitudes and emotions towards entities such as products, services, organizations, individuals, issues, events, 


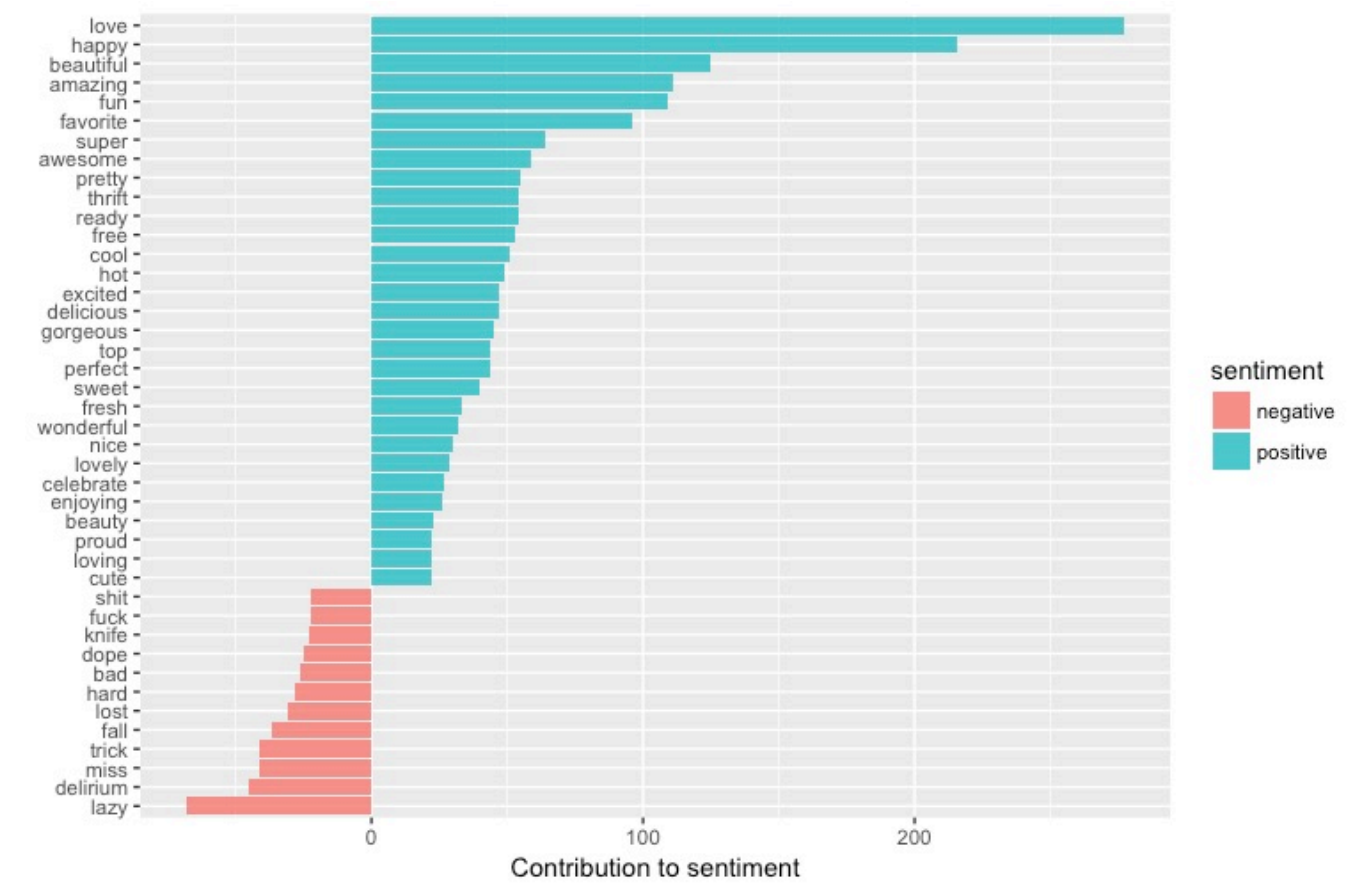

Figure 6: Top Terms contributing to Positive and Negative Sentiment sukawa and Yi 2003). Dictionaries of words annotated for different forms of sentiment are used to classify matching terms in a corpus, enabling the researcher an overall sentiment assessment of a text. For this study, the bing corpus of positive and negative words were used (Liu et al. 2016) with the tidytext package in R (Silge and Robertson 2016). A graph representing the top positive and negative terms (occurring at least 20 times) present in the Mission Instagram corpus is shown in Figure 6.

topics, and their attributes expressed in a written text" (Liu 2015: 7; Na-

The Mission Instagram corpus appears to have a positive bias, with 30 terms occurring more than 20 times contributing positive sentiment compared to 12 negative terms. Positive terms framing posts are seen to relate 
to emotions ('love' / 'loving', 'happy', 'excited', 'enjoying', 'proud'), descriptions ('beautiful', 'amazing', 'fun', 'super', 'awesome', 'delicious', 'gorgeous', 'wonderful', 'cute') and specific activities ('thrift', 'celebrate') while negative terms framing posts relate to states ('lazy', 'miss', 'lost'), descriptions ('hard', 'bad') or pejoratives ('shit', 'fuck'). Interestingly, the emoji 'knife' also is a frequent contributor to negative post sentiment.

The positive sentiment bias present in Mission Instagram posts is also observed in its most frequent terms. A word cloud of the top 50 of these frequent terms is shown in Figure 7. In addition to frequent mentions of place either by name or hashtag (i.e. 'San', 'Francisco' and 'sanfrancisco'; 'Dolores', 'Park' and 'dolorespark') terms suggestive of positive framing such as 'good', 'new', 'great' or emojis suggestive of positive framing 'heavy black heart' (the red heart emoji) are also present. Interestingly, the frequent occurrence of 'street art' in the corpus suggests prevalent engagement with the Mission's physical LL on this larger scale.

While a look at overall term sentiment and frequencies provides some insight on the nature of the Instagram corpus, I am interested in identifying specific discourse themes or topics that users post about. One way of categorizing these broader topics is by identifying inherent structures or relationships present in the distribution of terms across the corpus using topic modeling. Topic modeling is a probabilistic modeling technique commonly used in computational and corpus linguistics to identify structures within a large set of documents (Blei and Lafferty 2009; Grün and Hornik 2011; Wood 2014; Graham and Ackland 2016). Topic models use an iterative algorithm to assign and group terms in a corpus to a pre-determined number of topics 


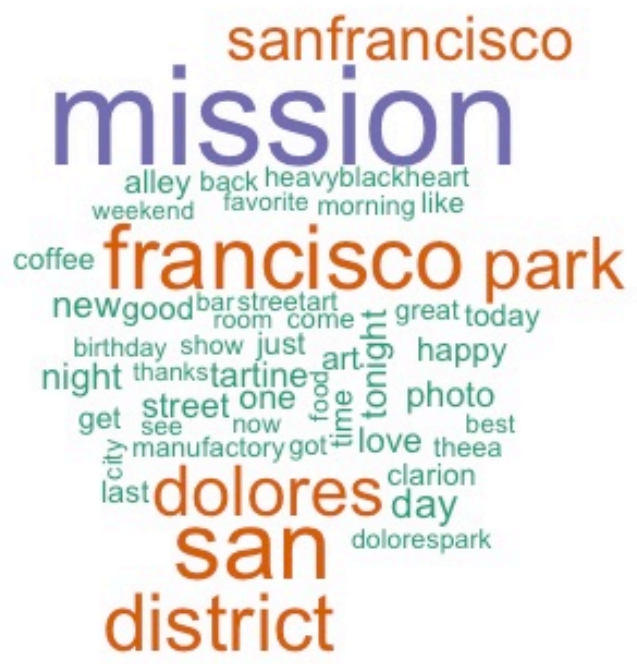

Figure 7: Word Cloud of Top 50 Terms

,

at

t

ass

.
to

.

3

4

485

486

487

set by the researcher. In the first pass, terms in documents (or for this study, words in individual posts) are assigned a topic (represented by a number) at random. This provides a proportion of terms assigned to a topic in this tweet as well as the proportion of how many times this same term has been assigned the same topic across the corpus. These proportions are then used to calculate the probability for the term's topic assignment for the next pass of the algorithm. This process is repeated a large number of times (specified by the researcher) until each term is assigned a particular topic and each document is assigned a topic based on the topic probabilities of the terms contained within it (Awati 2015; Blei 2012).

For this study, I ran a 5 topic Latent Dirichlet Allocation (LDA) algorithm with Gibbs sampling using the topicmodels package in R (Grün and Hornik 
2011). A table of the 16 top terms for each topic is shown in Table 1.

\begin{tabular}{|c|c|c|c|c|}
\hline Art & Occasion & Place & Food & Outdoors/Leisure \\
\hline sanfrancisco & tonight & mission & tartine & park \\
\hline street & night & $\operatorname{san}$ & coffee & dolores \\
\hline alley & happy & francisco & manufactory & day \\
\hline art & party & district & bar & love \\
\hline clarion & birthday & photo & morning & time \\
\hline streetart & sunday & sanea & amazing & city \\
\hline chapel & friends & drafthouse & elbo & dolorespark \\
\hline missionea & fun & alamo & theea & favorite \\
\hline valencia & halloween & igerssf & food & beautiful \\
\hline smilingfacewithheartshapedeyes & friday & ceramics & weekend & bear \\
\hline life & week & excited & sparkles & cafe \\
\hline california & saturday & fran & fire & people \\
\hline heavyblackheart & music & heart & brunch & $\operatorname{dog}$ \\
\hline facewithtearsofjoy & cinema & los & sfmanufactory & lazy \\
\hline mural & amnesia & districtea & chocolate & finally \\
\hline missiondistrict & house & spca & bakery & twohearts \\
\hline station & theea & armorykinkcom & bread & club \\
\hline graffiti & live & iea & dance & dont \\
\hline cream & tomorrow & cha & ive & stop \\
\hline taco & toea & heath & hotbeverage & blacksunwithrays \\
\hline
\end{tabular}

Table 1: Top 20 Terms per Topic

489 more direct depictions of the Mission's LL topic (i.e. posts discussing Clarion Alley, a small street between Valencia and Mission filled with murals); an 'Occasion' topic that appears to revolve around specific events or celebrations ('birthday', 'tonight', 'sunday'); a topic related to marking place (framing posts with 'Mission' or other specific places such as the restaurant 
Figure 8.

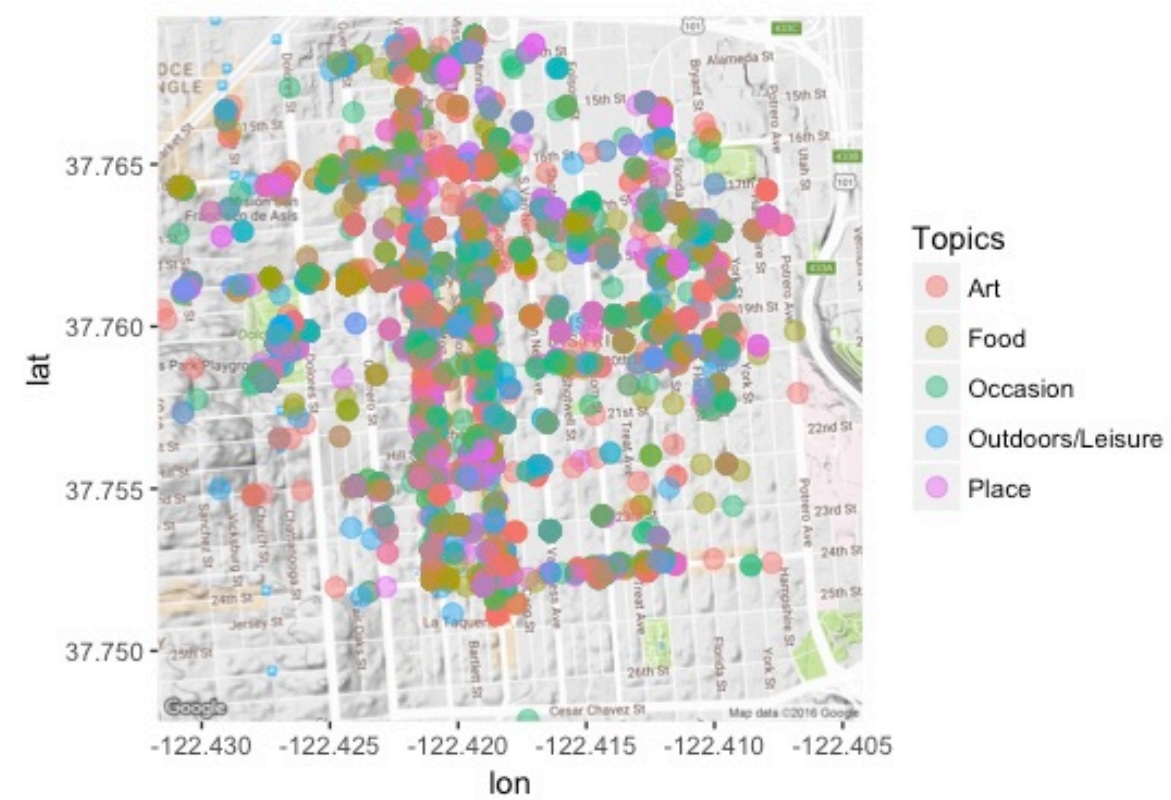

Figure 8: Geographic Distribution of Topics ${ }^{5}$

At first glance, there does not appear to be any clear differences in post

\footnotetext{
${ }^{5}$ Map obtained with the ggmap package in R (Kahle and Wickham 2013).
} 
distribution, but by subsetting the data and zooming in on specific areas in the map interesting patterns emerge. An example of this is shown in Figure 9, which shows a map of Mission posts with 'Place' and 'Occasion' topics removed.

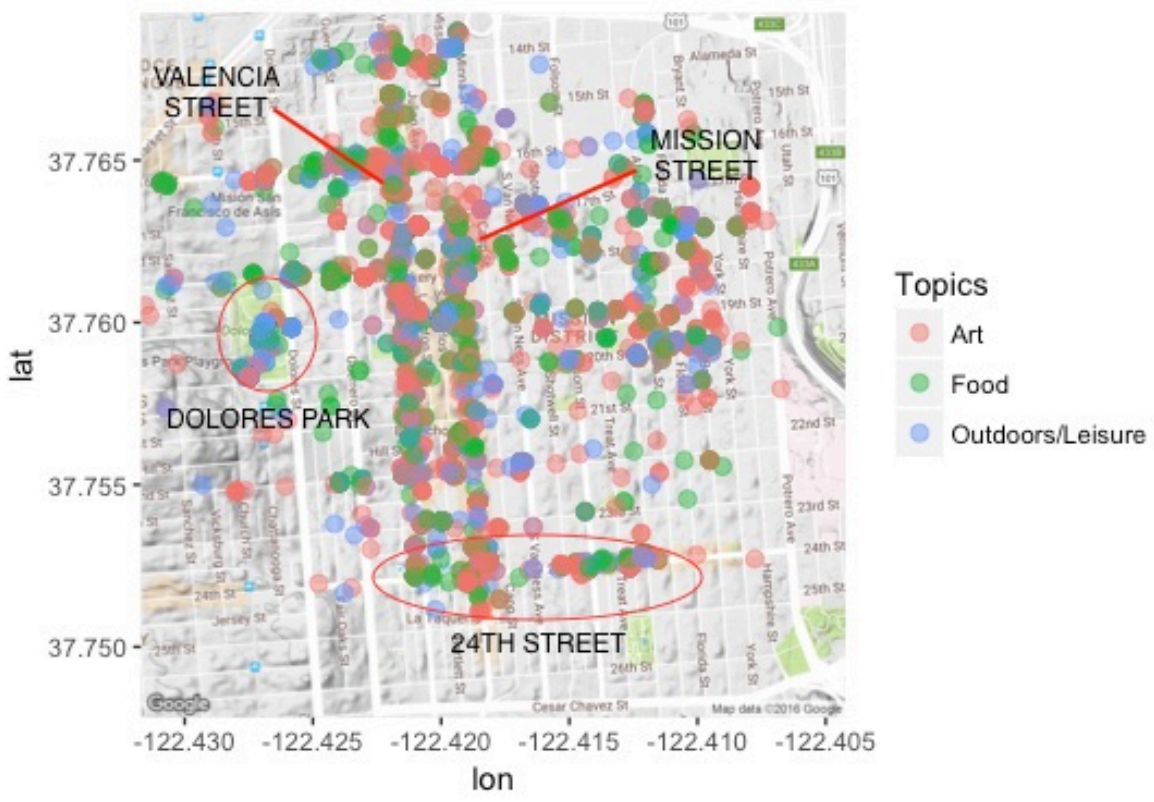

Figure 9: Subset Map of 'Art', 'Food', 'Outdoors/Leisure' Mission with the 'Art' and 'Food' topic removed.

This pattern is echoed in 24th street, as shown in the closer view of 


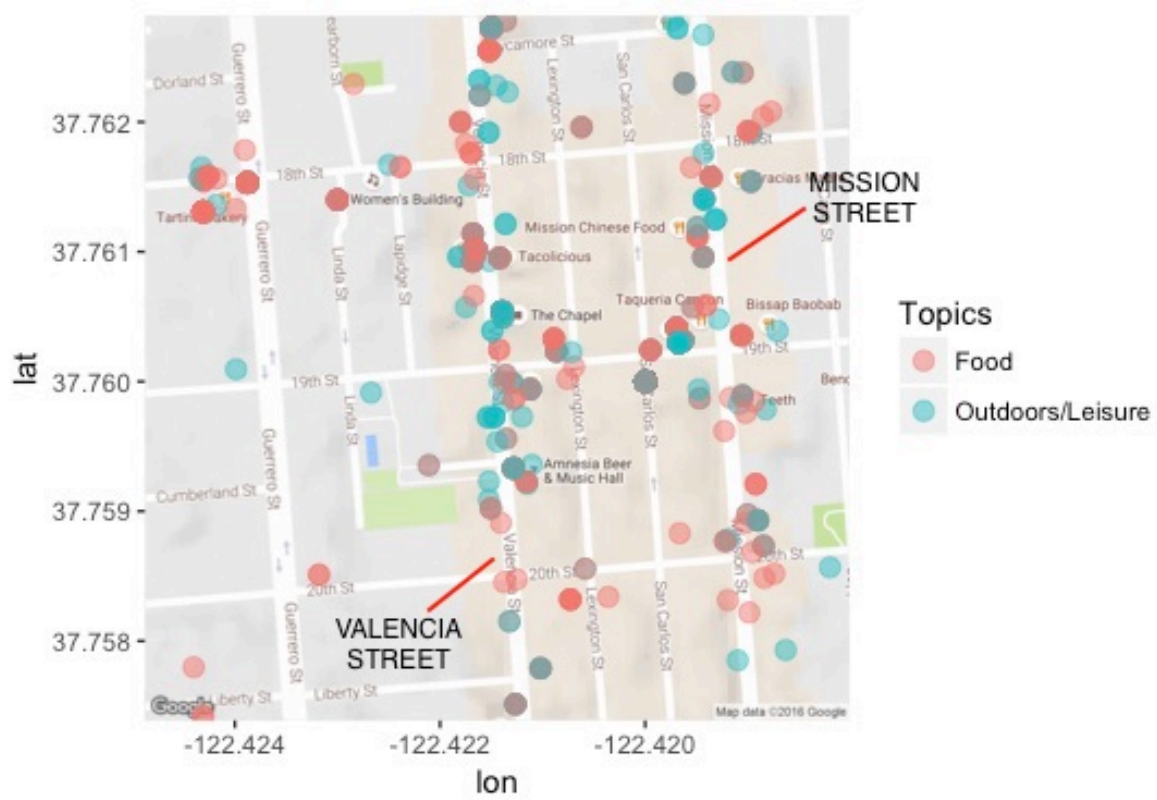

Figure 10: Subset and Zoom of Valencia and Mission, 'Food' vs. 'Outdoors/Leisure'

all topics in Figure 11. Compared to the other main streets of Valencia and Mission, 24th has far fewer posts. As the 'least gentrified' street in the neighborhood, it is interesting to see this sparsity on 24th, especially as pockets of posts re-appear at pockets of 24th aligned with establishments associated with 'gentrification' such as Wise Sons Jewish Delicatessen and Philz Coffee ${ }^{6}$. Posts classified under the 'Food' topic are common, and 'Art'

\footnotetext{
${ }^{6}$ While the owner of Philz Coffee has occupied this space since the 1970s and transformed it into a coffee shop in 2003, it and its specialty delicatessen neighbor across the street share features of establishments frequented by and understood as 'for' a newlyarrived higher-income clientele. Such features include emphasis on organic, locally-sourced food (with accompanying higher prices), increased specialization and commodification of that specialization's authenticity through selective references: a Jewish delicatessen with "Matzo Ball Soup - not at good as your bubbe's"; "Philz Coffee: One Cup at a Time ...
} 

can be seen.

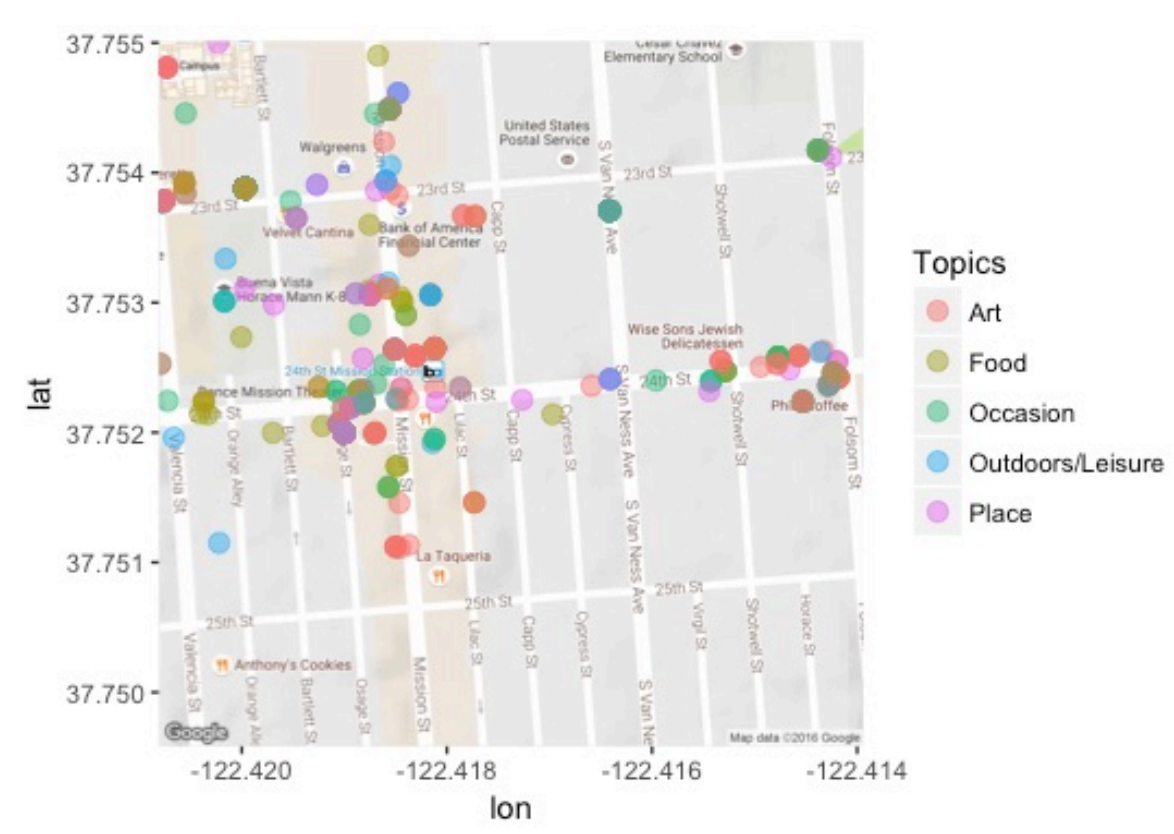

Figure 11: Topics on 24th

is prevalent in the intersection of 24th and Mission, where many large murals

Food and Art as topics thus appear to be spread out across the Mission, whereas Outdoors/Leisure is more frequent north of 24th on Mission (to some extent) and Valencia street. Posts under this topic of leisure (posts containing terms such as 'love', the palm tree emoji, the cocktail emoji, the wineglass emoji) appear to be concentrated in the more gentrified parts of the neighborhood.

buying only the highest quality green beans to ensure a perfect taste experience"; "Visionary FARINA founders embarked on a mission to bring an authentic northern Italian experience to terra Americana ... FARINA doesn't just approximate the cuisine of Liguria, it's the real thing" 
A similar pattern in seen in the distribution of the 'Occasion' and 'Place' topic, shown in Figure 12. "Occasion" (posts discussing a specific event or special occasion) are fairly spread out, whereas 'Place' posts, posts that discuss specific places in the Mission (perhaps to draw attention to the poster being at a certain location, or the location as part of the post discourse), appear to favor Valencia street over other locations.

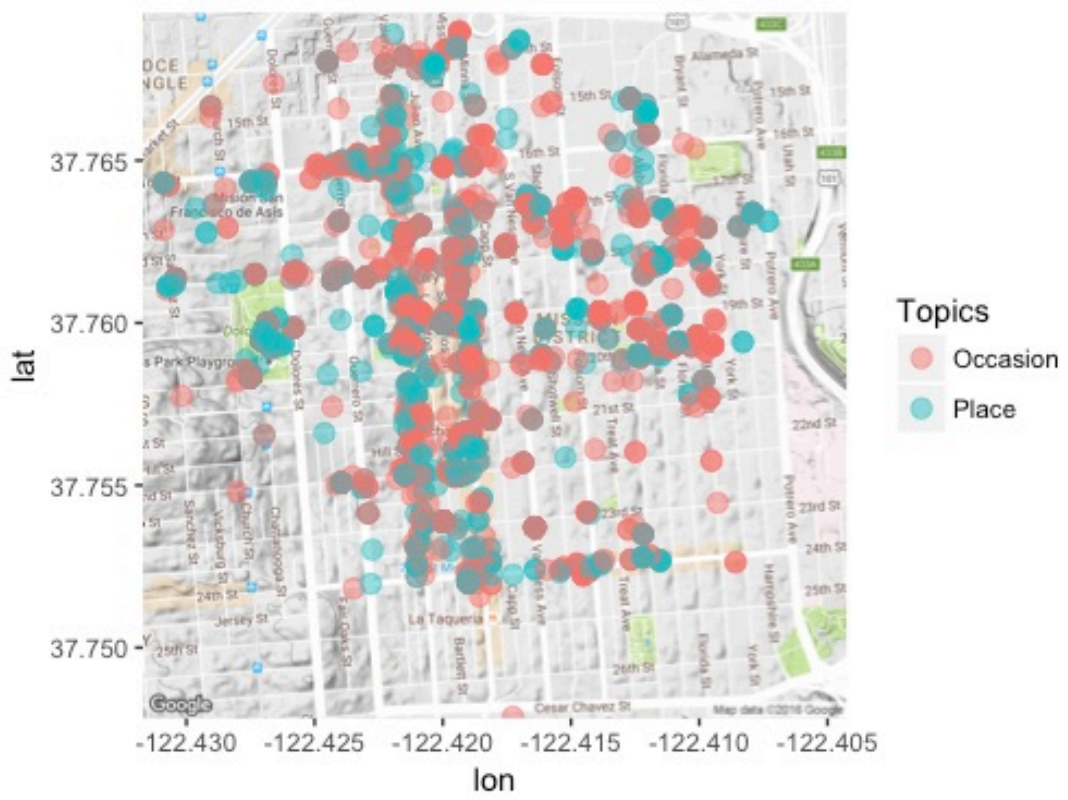

Figure 12: 'Occasion' v. 'Place'

While it is not possible to establish a causal link with the data available of gentrification and these topics, it is possible to discuss the interesting cooccurrence of these topics and a colloquial understanding of these areas as the most gentrified of the neighborhood. The most gentrified areas appear to generate posts centered on recreation, relaxation or on drawing attention to 'being' in a particular place. While the very act of geotagging does 
serve to bring attention to this kind of 'being', the producers of these posts have underscored this geotagging with accompanying, clarifying or elaborating prose. This is in contrast with other topics found more consistently throughout the Mission, those that focus on food or dining, celebrating or observing an event or holiday or observance of neighborhood art. These differences might be categorized as emphasis of states over activities, experience over enterprise. As these posts are positioned as the interpretant aspect of the LL, these topics could also be categorized in terms of the different ways in which their interpretants are brought about. The Outdoors/Leisure and Place topic posts can be described as rhematic in that their object is referenced in terms of the qualities it possesses ('beautiful', 'favorite', 'excited', red heart emoji, etc.) while Art, Occasion and Food appear to be dicents or dicisigns, achieving reference through "saturated predicates" (tagging a photo as '\#streetart', '\#brunch', using the 'face savouring delicious food' emoji or the 'knife and fork' emoji, writing 'Happy Birthday X', i.e. tagging to establish 'this is a photo of X') (Atkin 2013; Peirce 1955). A mapping of this division is provided in Figure 13.

These visualizations of topic distribution not only provide further contextualization for understanding the Mission's conceptual LL but serve as a strong reminder of the limits of social media to provide 'evidence' of an area's context as whole. As seen in these maps, posts are far from evenly distributed - the entire geographic area of the Mission is not covered nor, we must assume, are the thoughts of all those who move through it. It is significant, however, when these posts are fully considered as selective and subjective projections. The parallel Mission, the conceptual LL of Instagram, 


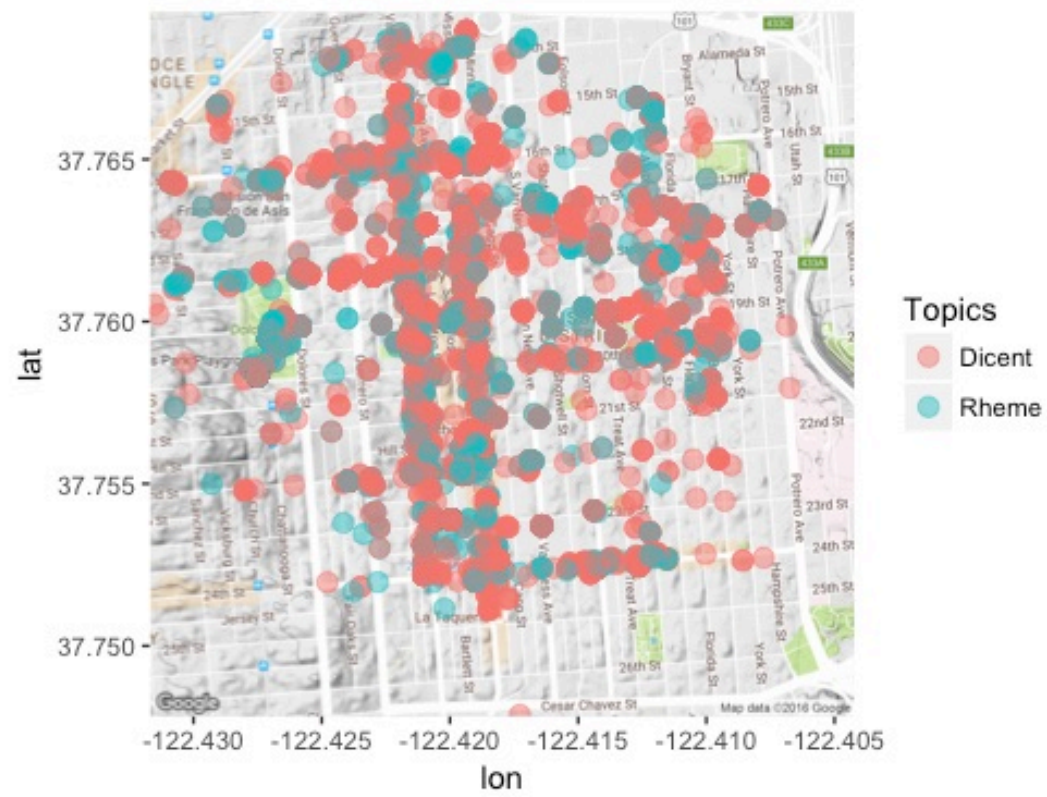

Figure 13: Dicent v. Rhematic Posts

is a positively framed space, discussing primarily enjoyable states or activities. There is a division between more and less gentrified areas and the types of enjoyment most frequently discussed, however en masse, the conceptual LL shows a positive subjective bias. Analysis of most frequent terms and inherent topics show no substantial mention of gentrification or any related topics such as displacement, no-fault evictions, inequality or increasing rent costs. The significance of this is best articulated via an understanding of the "semiotics of silence" (Kallen 2002; Jaworski 1993), in which the power of absence to speaks as much, if not more at times than presence, and silence resonates as erasure. For the Instagram Mission, gentrification is silenced and inequitable processes erased.

Such erasure speaks to, on the one hand, the inherent nature of social 
media as a positivity-biased space, with a tendency to only discuss or share pleasant or enviable experiences, and on the other, the discrepancy between projected digital places and their physical correlates. In this sense, Instagram can be thought of a sort of sieve, separating the unpleasant from the agreeable - the process of taking a picture, tagging and (optionally) commenting on it as the "simplest of interpreting agents" (Kockelman 2013: 37). It is in this sense the idea of the conceptual LL is reiterated: geotagged social media should be considered as the interpretant echo of the place in which they are situated by users. As a sieve, the process of posting on Instagram has to "take on (and not just take in) features of the substances [it] sieve[s], if only as 'inverses' of them ... in some sense, all sieves are inverses or even shadows of the substances they sort" (Ibid.: 36). Study of the conceptual, interpretant or shadow place constituted by geotagged social media thus not only informs our understanding of what makes it through the sieve (that is, what are the overarching features of acceptable posts or topics) but the systemic or ideological components of the sieve itself. In the case of the Mission, we observe a preference towards discussing art, special occasions, the place captured in the photo, food and leisurely activities, and a systemic exclusion of any kind of reference or acknowledgement of the uncomfortable reality of inequitable displacement.

\section{Concluding Remarks}

The significance of these findings is found in returning to the metapragmatic power of social media post content to simultaneously occupy and order. It is through the subjective and selective displays that the Mission is 
re-produced, re-contextualized and re-established virtually, and as shown in the example in Figure 5, the term virtual can be quite misleading. Social Networks are, after all, social networks, consisting of interpersonal relationships and interaction. The term used by Instagram to describe relationships between one user and another (i.e. who is seeing whose posts), 'following' speaks directly to the social significance and dynamics of the Instagram environment. Networks of follower-following encapsulate the idea of semiotic chains of transmission, through which relationships between signs and meanings are produced, shared and consumed (Agha 2007). The act of posting is a link mediating content and meaning, and the act of geotagging a link mediating place and meaning: the conceptual LL and the networks through which it moves constitute semiotic chains in which discourses of what the Mission means and what the Mission is are circulated. That gentrification is absent from the mass-mediated conception of the neighborhood is of great theoretical and social significance, simultaneously upholding the idea that the circulation of meanings or reflexive activity "articulate" subjective cultural value (Silverstein 2003; Agha 2003), and demonstrating the potential dangers of this process whereby prevalent inequities and injustices are erased. Such insights on the large-scale characteristics and consequences of the Mission's conceptual LL demonstrate the value of combining qualitative assessment and computational analysis. As social media continues to increasingly mediate individuals' social and semiotic experiences, the necessity of using it to track these very processes becomes equally important. Tools such as text mining, sentiment analysis and topic modeling reveal the hidden underlying structures of the conceptual LL, enabling unprecedented access and 
insight on the social production of place.

Agha, A. (2003). The social life of cultural value. Language $\&$ communication, $23(3): 231-273$.

Agha, A. (2007). Language and social relations. Number 24. Cambridge University Press.

Amos, H. W. (2016). Chinatown by numbers. Linguistic Landscape, 2(2):127156.

Atkin, A. (2013). Peirce's theory of signs. In Zalta, E. N., editor, The Stanford Encyclopedia of Philosophy. Metaphysics Research Lab, Stanford University, summer 2013 edition.

Atkinson, R. and Bridge, G. (2005). Introduction. In Atkinson, R. and Bridge, G., editors, Gentrification in a Global Context: The New Urban Colonialism, chapter 1. Routledge.

Awati, K. (2015). A gentle introduction to topic modeling using R. https://eight2late.wordpress.com/.

Backhaus, P. (2006). Multilingualism in Tokyo: A look into the linguistic landscape. In Gorter, D., editor, Linguistic Landscape: A New Approach to Multilingualism, chapter 3, pages 52 - 66. Multilingual Matters.

Barni, M. and Bagna, C. (2015). The critical turn in LL: New methodologies and new items in LL. Linguistic Landscape: An international journal, $1(1-2): 6-18$. 
Basta Ya (1970). 'BART Changes the Mission'. http://www.foundsf.org.

Ben-Rafael, E., Shohamy, E., Hasan Amara, M., and Trumper-Hecht, N. (2006). Linguistic landscape as symbolic construction of the public space: The case of israel. In Gorter, D., editor, Linguistic Landscape: A New Approach to Multilingualism, chapter 1, pages 7 -30. Multilingual Matters.

Blackwood, R. (2015). Ll explorations and methodological challenges: Analysing France's regional languages. Linguistic Landscape, 1(1-2):3853.

Blei, D. M. (2012). Probabilistic topic models. Communications of the ACM, $55(4): 77-84$.

Blei, D. M. and Lafferty, J. D. (2009). Topic models. In Srivastava, A. N. and Sahami, M., editors, Text Mining: Classification, Clustering, and Applications, chapter 4, page 34. CRC Press.

Blommaert, J. (2013). Ethnography, superdiversity and linguistic landscapes: Chronicles of complexity, volume 18. Multilingual Matters.

boyd, d. m. and Ellison, N. B. (2007). Social network sites: Definition, history, and scholarship. Journal of Computer-Mediated Communication, 13(1):210-230.

Cabanatuan, M. and Alexander, K. (2014). 'Google bus backlash: S.F. to impose fees on tech shuttles'. http://www.sfgate.com/bayarea/article/Google-bus-backlash-S-F-toimpose-fees-on-tech-5163759.php. 
Cenoz, J. and Gorter, D. (2006). Linguistic landscape and minority languages. In Gorter, D., editor, Linguistic Landscape: A New Approach to Multilingualism, chapter 5, pages $67-80$. Multilingual Matters.

Coupland, N. (2012). Bilingualism on display: The framing of Welsh and English in Welsh public spaces. Language in Society, 41(1):1-27.

Coupland, N. and Garrett, P. (2010). Linguistic landscapes, discursive frames and metacultural performance: The case of Welsh Patagonia. International Journal of the Sociology of Language, 2010(205):7-36.

Danneman, N. and Heimann, R. (2014). Social Media Mining With R. Packt Publishing.

Dovchin, S., Sultant, S., and Pennycook, A. (2015). Relocalizing the translingual practices of young adults in mongolia and bangladesh. Translation and Translanguaging in Multilingual Contexts, 1(1):4- 26.

Duggan, M., Ellison, N., Lampe, C., Lenhart, A., and Madden, M. (2015). Social media update. http://www.pewinternet.org/2015/01/09/socialmedia-update-2014/.

Dunlevy, D. (2016). Blurred lines: The effect of regional borders on the LL in Northern Spain. Linguistic Landscapes International Workshop 8.

Feinerer, I. and Hornik, K. (2015). tm: Text Mining Package. R package version $0.6-2$.

Foucault, M. (1984). The Foucault reader. Pantheon. 
Garvin, T. (2010). Responses to the linguistic landscape in Memphis, Tennessee: An urban space in transition. Linguistic landscape in the city, pages 235-251.

Gentry, J. (2015). twitteR: R Based Twitter Client. R package version 1.1.9.

Glass, R. (1964). Aspects of change. In Brown-Saracino, J., editor, The Gentrification Debates: A Reader. Routledge.

Goffman, E. (1974). Frame analysis: An essay on the organization of experience.

Gorter, D. (2006). Introduction: The study of the linguistic landscape as a new appraoch to multilingualism. In Gorter, D., editor, Linguistic Landscape: A New Approach to Multilingualism, pages 1 -6. Multilingual Matters.

Gouws, S., Metzler, D., Cai, C., and Hovy, E. (2011). Contextual bearing on linguistic variation in social media. In Proceedings of the Workshop on Languages in Social Media, LSM '11, pages 20-29, Stroudsburg, PA, USA. Association for Computational Linguistics.

Graham, T. and Ackland, R. (2016). Topic Modeling of Tweets in R: A Tutorial and Methodology. https://www.academia.edu/.

Grün, B. and Hornik, K. (2011). topicmodels: An R package for fitting topic models. Journal of Statistical Software, 40(13):1-30.

Herring, S. C. (2012). Grammar and electronic communication. In The Encyclopedia of Applied Linguistics. Blackwell Publishing Ltd. 
Instagram (2016). 'About Us'. https://www.instagram.com/about/us/.

Ivkovic, D. and Lotherington, H. (2009). Multilingualism in cyberspace: conceptualising the virtual linguistic landscape. International Journal of Multilingualism, 6(1):17-36.

Jaworski, A. (1993). The power of silence: Social and pragmatic perspectives, volume 1 of Language and Language Behaviors. Sage Publications.

Jaworski, A. (2015). Word cities and language objects:'love' sculptures and signs as shifters. Linguistic Landscape: An international journal, 1(12):75-94.

Jaworski, A. and Thurlow, C. (2010). Introducing semiotic landscapes. In Jaworski, A. and Thurlow, C., editors, Semiotic landscapes: Language, image, space, Advances in Sociolinguistics, pages 1 - 42. Continuum International Publishing Group.

Jaworski, A. and Yeung, S. (2010). Life in the garden of eden: The naming and imagery of residential hong kong. In Elana Shohamy, E. B.-R. and Barni, M., editors, Linguistic Landscape in the City, chapter 9, pages 153181. Multilingual Matters Bristol.

Jones, R. H. (2010). Cyberspace and physical space: Attention structures in computer mediated communication. In Jaworski, A. and Thurlow, C., editors, Semiotic landscapes: Language, image, space, pages 151-167. Continuum International Publishing Group.

Kahle, D. and Wickham, H. (2013). ggmap: Spatial visualization with ggplot2. The R Journal, 5(1):144-161. 
Kallen, J. (2010). Changing landscapes: Language, space and policy in the dublin linguistic landscape. In Jaworski, A. and Thurlow, C., editors, Semiotic landscapes: Language, image, space, Advances in Sociolinguistics, chapter 1, pages 41 - 58. Continuum International Publishing Group.

Kallen, J. L. (2002). L'idée de nation: Le timbre-poste grec (1924-1982). Protée, 30(2):73-84.

Kockelman, P. (2013). The anthropology of an equation. sieves, spam filters, agentive algorithms, and ontologies of transformation. HAU: Journal of Ethnographic Theory, 3(3):33-61.

KTVU News (2015). 'Mission District anti-eviction protesters take over SF City Hall'. http://www.ktvu.com/news/4586188-story.

Lefevbre, H. (1991). The production of space. Trans. Donald NicholsonSmith. Oxford, UK: Blackwell.

Liu, B. (2015). Sentiment Analysis: Mining Opinions, Sentiments and Emotions. Cambridge University Press.

Liu, Bing and Collaborators (2016). Bing sentiment lexicon. https://www.cs.uic.edu/ liub/FBS/sentiment-analysis.html.

Lou, J. J. (2010). Chinese on the side: The marginalization of chinese in the linguistic and social landscapes of chinatown in washington, d.c. In Elana Shohamy, E. B.-R. and Barni, M., editors, Linguistic Landscape in the City, chapter 6, pages 96-114. Multilingual Matters. 
Lyons, K. and Rodríguez-Ordóñez, I. (2015). Public legacies: Spanish-english (in)authenticity in the linguistic landscape of Pilsen, Chicago. University of Pennsylvania Working Papers in Linguistics, 21(2).

Macris, D., Hart, N., Luellen, M., and Weintraub, M. (2007). City within a city: Historic context statement for San Francisco's Mission District.

Malinowski, D. (2009). Authorship in the linguistic landscape: A multimodal-performance view. In Shohamy, E. and Gorter, D., editors, Linguistic Landscape: Expanding the Scenery, chapter 7, pages 107-125. Routledge.

Nasukawa, T. and Yi, J. (2003). Sentiment analysis: Capturing favorability using natural language processing. In Proceedings of the 2nd international conference on Knowledge capture, pages 70-77. ACM.

Papen, U. (2012). Commercial discourses, gentrification and citizens' protest: The linguistic landscape of Prenzlauer Berg, Berlin. Journal of Sociolinguistics, 16(1):56-80.

Peck, A. and Banda, F. (2014). Observatory's linguistic landscape: semiotic appropriation and the reinvention of space. Social Semiotics, 24(3):302323.

Peirce, C. S. (1955). Philosophical Writings of Peirce. Dover Publications.

San Francisco Chronicle (2014). 'A Changing Mission'. http://www.sfchronicle.com/the-mission/. 
Shields, R. (1987). Henri Lefebvre: La production de 1 'espace. An English Précis of Henri Lefebvre's La Production de l'Espace'University of Sussex, Brighton UK Urban and Regional Studies Working Paper, 63.

Silge, J. and Robinson, D. (2016). tidytext: Text mining and analysis using tidy data principles in r. JOSS, 1(3).

Silverstein, M. (2003). Indexical order and the dialectics of sociolinguistic life. Language \& Communication, 23(3-4):193 - 229. Words and Beyond: Linguistic and Semiotic Studies of Sociocultural Order.

Smith, N. (1979). Toward a theory of gentrification a back to the city movement by capital, not people. Journal of the American Planning Association, 45(4):538-548.

Squires, L. (2010). Enregistering internet language. Language in Society, $39(4): 457-492$.

Stroud, C. and Mpendukana, S. (2009). Towards a material ethnography of linguistic landscape: Multilingualism, mobility and space in a South African township. Journal of Sociolinguistics, 13(3):363-386.

Sykes, J., Oskoz, A., and Thorne, S. (2008). Web 2.0, synthetic immersive environments, and mobile resources for language education. CALICO Journal, 25(3):528-546.

Twitter Developer Documentation (2016). 'The Search API'. https://dev.twitter.com/rest/public/search. 
802 Vandenbroucke, M. (2016). Socio-economic stratification of English in glob803 alized landscapes: A market-oriented perspective. Journal of Sociolinguis$804 \quad$ tics, 20(1):86-108.

805

806

VSCO (2016). 'App Store Editor's Notes'. https://itunes.apple.com/us/app/vsco/id588013838?mt=8.

Waksman, S. and Shohamy, E. (2016). Mediating LL: Focus on tour guides. Linguistic Landscapes International Workshop 8.

Wood, I. (2014). Recent advances and applications of probabilistic topic models. AIP Conference Procedeeings, 1636(1):124 - 130.

Zappavigna, M. (2011). Ambient affiliation: A linguistic perspective on twitter. New media \&s society, 13(5):788-806.

Zoladz, L. (2014). The \#art of the hashtag. http://pitchfork.com/features/ordinary-machines/9351-hashtags/. 